\title{
Developing Students' Argument Skills Using Socioscientific Issues in a Learning Unit on the Fossil Fuel Industry and Its Products
}

\author{
Bureerat Suephatthima, Chatree Faikhamta* \\ Department of Education, Faculty of Education, Kasetsart University, Bangkok, Thailand \\ *Corresponding Author: chatreechem@yahoo.com
}

\section{ABSTRACT}

Argument skills play a crucial role in fostering students' scientific literacy. Students who possess such skills can employ reason and evidence to make decisions. This classroom action research was aimed at investigating the best practices for teaching chemistry to promote argument skills through socioscientific issues (SSI). The participants were 46 Thai students in Grade 12 (students aged approximately 17 years old) studying petroleum chemistry in the first semester of the 2014 academic year. To research my own teaching, I collected data from classroom observation, my reflective journals, the students' reflective journals, and an argument skill questionnaire (ASQ). Debating on petroleum-related issues helped the students to practice and improve their reasoning skills, and it showed them the importance of using evidence to formulate a reliable argument. The competition to answer questions in class also allowed students to practice reasoning. Finally, the ASQ results indicate that teaching through SSI can improve students' argument skills. The implication of the pedagogy of argumentation in science classroom is discussed.

KEY WORDS: argumentation; secondary students; chemistry; questionnaires

\section{INTRODUCTION}

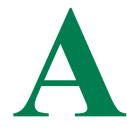

rgumentation plays an important role in learning science. Based on constructivism, knowledge of science comes from interpretation or using prior knowledge to make the meaning of evidence (Berk and Winsler, 1995; Berland and McNeill, 2010; Yilmaz et al., 2017). Scientific knowledge can be argued, proved, and negotiated (Driver et al., 1994). Argumentation is a process that takes place when at least two people argue in support of their own claims using so-called argumentive discourse (Kuhn and Udell, 2003). Since argumentation involves using arguments to support one's standpoint, the argument can be regarded as the product of argumentation.

Argumentation in science education has been discussed over the past decade (Erduran and Jimenez-Aleixandre, 2012). Osborne et al. (2004) suggested that data, claim, warrant, and backing are the components of an argument, whereas argumentation is the process of developing an argument. A good argument can be judged by the number and quality of the aforementioned components of the argument. Maloney and Simon (2006) explained that a good argument occurs when one can protect one's claims from counterarguments using evidence and reason. The quality of an argument can be evaluated according to how compelling the reasons supporting the claim are. Kuhn and Udell (2003) observed three levels of an argument's quality in their study: (1) Functional arguments addressed purposes or functions, (2) non-functional arguments arose when students did not address the functions of the claim and instead focused on the conditions under which it should be administered, rather than its purposes, and (3) non-justificatory arguments - the lowest level - were regarded as having little or no argumentative force.

As seen, the quality of an argument is determined by the argument's various components. Toulmin (2003) specified the six common components of an argument, known as Toulmin's argument pattern (TAP), as shown in Figure 1.

TAP starts when one has data and makes a claim. Then, one attempts to enhance the reliability of the claim by explaining how the data support the claim. These explanations are warrants. To make warrants reliable, one uses facts, research, numbers, news, graphs, etc., to show the plausibility of the warrants (i.e., backing). However, another person may disagree with the claim and try to reject it by refuting the reliability of the warrants supporting the claim. Statements that can reduce the the reliability of warrants are called rebuttals. Finally, as the claim is not $100 \%$ reliable, one uses words indicating the plausibility of the claim, called qualifiers.

Although TAP has been applied widely in the argumentation research, distinguishing between data and warrants has posed a problem because data can be used as warrants (Zeidler, 2003). Therefore, some studies have focused on only one of them to assess argument skills. Lin and Mintzes (2010) studied students' argument skills by observing five components of an 
argument, namely claim, warrant, counterargument, supportive argument, and backing. Moreover, some researchers have evaluated argument skills by examining counterargument, supportive argument, and backing (Brem and Rips, 2000).

Among the components listed in Table 1, (1) claims and (2) warrants are the basic components to argue, (3) backings support the warrants, (4) counterarguments show that students understand what others think, and if students can make arguments and counterarguments at the same time, this evidences multiperspective thinking and a solid argument ability, and (5) rebuttals can disprove counterarguments, denoting high-quality arguments. If students can make rebuttals, it means that they have evaluated the reliability of the claim and counterclaim (Kuhn, 1991).

The aim of this study was to develop the argument skills of students by focusing on the five components of claim, warrant, backing, counterargument, and rebuttal. The definitions of these terms for this study are based on Toulmin's framework (2003):

- Claim: The statement being argued.

- Warrants: General, hypothetical, and logical statements serving as a bridge between the claim and data.

- Backing: A statement supporting the warrants (i.e., proving the warrants is true).

- Counterargument: Warrants of a counterclaim.

- Rebuttal: Statements serving to refute the counterargument.

Claims, warrants, and backings indicate that students have a sense of themselves, while counterarguments and rebuttals show that students have a sense of others.

Given its importance, argumentation should be addressed in science classrooms in general and in my classroom in

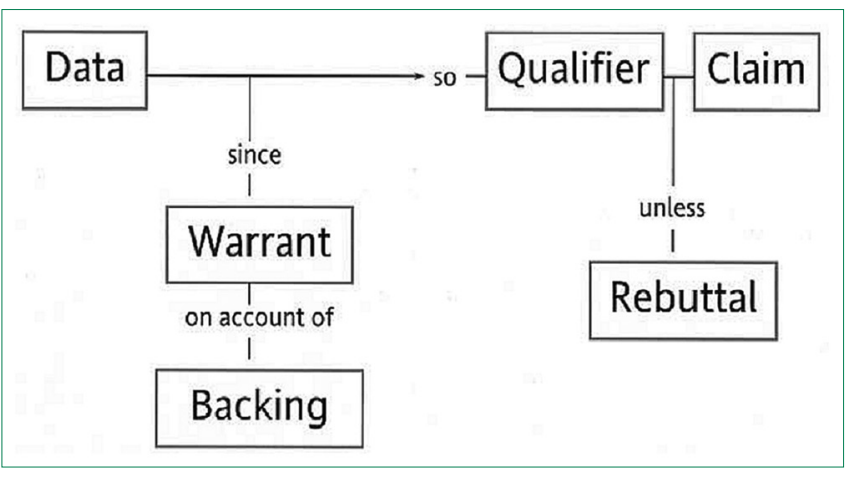

Figure 1: Components of an argument from Toulmin's argument pattern (Toulmin, 2003) particular. When I, the first author, began teaching chemistry to 42 Grade 12 students, I needed to help them develop their argument skills. I started my preliminary studies using an argument skills questionnaire (ASQ) to assess their prior argument skills. They had to argue whether liquid petroleum gas (LPG) or condensate natural gas (CNG) is suitable for vehicles. I found that all students could respond with a claim, and most of them (98\%) supported their claim with (a) warrant(s). Similarly, most of the students could respond to a counterargument $(90 \%)$. However, few students could use backings and rebuttals (30\% and $23 \%$, respectively). Thus, I sought an alternative approach to enhance our students' argument skills. Sadler (2011) and Zeidler et al. (2005) have suggested that teaching through socioscientific issues (SSIs) is an effective method for developing argument skills. SSIs are controversial social issues relating to science. They are illstructured, open-ended problems that have multiple solutions. SSI is utilized in science education to promote scientific literacy, which emphasizes the ability to apply scientific and moral reasoning to real-world situations.

Giving the students an issue that was relevant to their lives encouraged them to appreciate and engage in argumentation (Zohar and Nemet, 2002). However, since SSI is quite broad issues, controversial, and ill-structured, devising solutions is not easy. The teacher plays a vital role in guiding the students toward informing various dimensions of the issue at hand. Furthermore, the learning environment and activities should be carefully designed to help students make their own claims, supported by warrants, and develop backings for those warrants (Oulton et al., 2004). Zeidler and Nichols (2009) proposed a framework for teaching through SSI comprising two features. First, teachers should understand what students think about the topic; second, the issue must relate to the lesson. Then, the students can have contextualized argumentation. Therefore, I sought to develop my own teaching practice by examining the best practices for developing argument skills in Grade 12 students in the context of a learning unit on the fossil fuel industry and its products using SSI.

\section{METHODOLOGY}

\section{Research Method}

This study is an example of classroom action research underpinned by living theory (McNiff and Whitehead, 2005), in which I as a researcher research my own beliefs and practice. Participants were 42 Grade 12 students at a public school in Bangkok, Thailand. Of the participants, 5 were

Table 1: Components of an argument which have been studied before

\begin{tabular}{lllllllll}
\hline Research in argument & Claim & Data & Warrants & Backings & Qualifiers & Rebuttals & Counterargument & Evidence \\
\hline Toulmin (2003) & $\checkmark$ & $\checkmark$ & $\checkmark$ & $\checkmark$ & $\checkmark$ & $\checkmark$ & & $\checkmark$ \\
Lin and Mintzes (2010) & $\checkmark$ & & $\checkmark$ & & & $\checkmark$ & $\checkmark$ & $\checkmark$ \\
Osborne et al. (2004) & $\checkmark$ & $\checkmark$ & $\checkmark$ & $\checkmark$ & & & \\
Maloney and Simon (2006) & $\checkmark$ & $\checkmark$ & $\checkmark$ & $\checkmark$ & & & \\
\hline
\end{tabular}


males and 41 males. They were taking a chemistry course and voluntarily agreed to participate in this study. The chemistry course consisted of $3 \mathrm{~h}$ a week for 3 weeks, a total of $9 \mathrm{~h}$. The research comprised two cycles, with one issue per cycle. The issue in the first cycle concerned a Thai oil fund that had caused a controversy around 2013-2014. The oil fund faced many problems including a corrupt administration, high prices of petroleum products, and fairness in oil consumption. However, the Thai oil fund also subsidized the price of petroleum products, such as gasoline E20 and gasoline E85, which represent alternative energy sources. Accordingly, students had to decide whether or not the Thai oil fund should be shut down. The issue in the second cycle concerned the construction of a coal-fired power plant. Krabi is an attractive province in the southern part of Thailand. It is known for having one of the most beautiful beaches in the world. However, the electricity needs of the province have increased as the population increased. The electricity generating authority of Thailand wanted to construct a new coal-fired power plant in Krabi to meet the electricity demands of the tourism sector. However, local residents and NGOs staged anti-coal protests. Therefore, the students needed to decide whether or not the coal-fired power plant should be constructed in Krabi.

\section{Data Collection and Analysis}

Data were collected using my own reflective journal, student journals, and ASQ. The questionnaire adapted from Lin and Mintzes' (2010) ASQ comprised four open-ended questions regarding five components. For my ASQ, I separated question 1 of Lin and Mintzes' (2010) questionnaire into two questions. Accordingly, the ASQ in this study comprised five open-ended questions asking for five components of the argument. The five questions regarding whether the Thai oil fund should be shut down were as follows:

- Q1: Do you agree or disagree with shutting down the Thai oil fund? (assessing students' ability to make a claim)

- Q2: What are your reasons? (assessing students' ability to make warrants)

- Q3: What evidence might support your reasons? (assessing students' ability to generate backing)

- Q4: If somebody disagreed with the opinions you expressed in the first question, (s)he might have some reasons. What might these reasons be? (assessing students' ability to generate a counterargument)

- Q5: How would you convince somebody who disagreed with you if they had given the reasons in the fourth question? (Assessing students' ability to generate a rebuttal)

The study of Lin and Mintzes' (2010) indicated that, if students were unfamiliar with an issue for which they wanted to construct an argument, then most of them would not be able to construct the argument. Therefore, ASQ contained an informational scenario and five probing questions about the argument.

The quality of an argument can be evaluated from warrants. Kuhn and Udell (2003) used the criteria that, if warrants endorse the claim, the quality of the argument is better. They assigned three levels of argument quality: Functional arguments, non-functional arguments, and non-justificatory arguments. Functional arguments have high rationality. Their characteristics can be classified into three patterns: (1) The arguments infer that another choice has no or less efficiency, (2) the arguments indicate the advantage(s) of the claim, and (3) the arguments infer that the claim is justified. Nonfunctional arguments are conditionally rational. This type of argument has warrants only suitable for specific circumstances or the students do not mention the rationality of the warrants. Finally, non-justificatory arguments do not have any reason supporting the claim; therefore, they have no argument force, such as how popular the claim is or how long the claim has been used in the society.

The levels of argument quality mentioned above were adopted in this study. I designed rubric scores depending on the argument quality (Kuhn and Udell, 2003) and argument variety (Lin and Mintzes, 2010). According to Lin and Mintzes' (2010) scoring rubric, claims, warrants, backings, counterarguments, and rebuttals have their own scores, which are multiplied if the answers for each component vary. For example, the first question on Lin and Mintzes' (2010) ASQ asked for a claim and warrants regarding the following: "Do you agree with the construction of Ma-Guo National Park in Taiwan? Write down your opinion and reasons." A student answered "I agree... The National Park can protect animals from being hunted by humans." The student got one point for the claim (I agree) and two points for the two warrants; one was "the National Park can protect animals from being hunted by humans" and the other was "local economic development will be improved if many tourists come."

My criteria for argument skills analysis integrated argument quality (qualitative analysis) from Kuhn and Udell (2003) and argument variety (quantitative analysis) from Lin and Mintzes (2010), combined with the induction analysis of my work. I conducted both qualitative and quantitative analyses on the results obtained from ASQ. These are shown in Table 2.

\section{Findings}

\section{Students' argument skills}

Argument skills were collected from ASQ, which consisted of five open-ended questions asking for a claim, warrant(s), backing(s), counterargument, and rebuttal. The data were analyzed according to the criteria shown in Table 2.

The argument skills of the first and second cycles were analyzed, and the pre- and posttests were compared. Therefore, this argument skill section will cover three issues concerning the comparison of both cycles and the argument skills.

\section{Comparison of the Development of Argument Skills from Both Cycles}

The development of argument skills was observable from an increase in the sum of the rubric scores for all five components of ASQ. This development was divided into six levels as shown in Table 3. 
Table 2: Qualitative and quantitative analyses of argument skills

\begin{tabular}{|c|c|c|}
\hline Question & Group & Rubric score \\
\hline \multirow[t]{2}{*}{ 1. Claim } & $\mathrm{A}=$ can take a side & 1 \\
\hline & $\mathrm{B}=$ cannot take a side & 0 \\
\hline \multirow[t]{7}{*}{ 2. Warrants } & $\mathrm{A}+++=4$ justificatory reasons & 12 \\
\hline & $\mathrm{A}++=3$ justificatory reasons & 9 \\
\hline & $\mathrm{A}+=2$ justificatory reasons & 6 \\
\hline & $\mathrm{A}=1$ justificatory reason & 3 \\
\hline & $\mathrm{B}=$ conditional justificatory reasons & 2 \\
\hline & $\mathrm{C}=$ Non-justificatory reasons & 1 \\
\hline & $\mathrm{D}=$ No reason & 0 \\
\hline \multirow[t]{4}{*}{ 3. Backing } & $\mathrm{A}+=2$ pieces of evidence & 8 \\
\hline & $A=1$ piece of evidence & 4 \\
\hline & $\mathrm{B}=$ Other except evidence & 2 \\
\hline & $\mathrm{C}=\mathrm{No}$ answer & 0 \\
\hline 4. Counter- argument & The same as question number 2 & \\
\hline \multirow[t]{6}{*}{ 5. Rebuttal } & $\mathrm{A}^{+}=$more than 1 relevant and clear rebuttal & 12 \\
\hline & $\mathrm{A}=1$ relevant and clear rebuttal & 6 \\
\hline & $\mathrm{A}_{-}=$relevant but unclear rebuttal & 4 \\
\hline & $\mathrm{B}=$ irrelevant but clear rebuttal & 2 \\
\hline & $\mathrm{B}-=$ irrelevant and unclear rebuttal & 1 \\
\hline & $\mathrm{C}=$ no rebuttal & 0 \\
\hline
\end{tabular}

\begin{tabular}{ll}
\hline Table 3: Score change and development levels \\
\hline Score change & Development levels \\
\hline Increase of more than 20 points & Drastic development \\
Increase of $10-20$ points & High development \\
Increase of 5-9 points & Intermediate development \\
Increase of $1-4$ points & Some development \\
Same score & No development \\
Lower score & Deterioration \\
\hline
\end{tabular}

In the first cycle, students' argument skills showed higher development than in the second cycle. The number of students at each level is shown in Figure 2.

The first cycle showed more development in argument skills than the second cycle because, in the first cycle, students had highly improved in warrant, backing, counterargument, and rebuttal, while in the second cycle, students had slightly developed in those components. For example, there were 11 students in drastic and high development levels in the first cycle, but no one reached these levels in the second cycle. Besides, in the second cycle, up to 10 students had a deteriorated score.

\section{Argument skills in the first cycle}

In this cycle, argument skills were assessed through ASQ regarding the issue of whether the Thai oil fund should be abolished. The data were analyzed according to the criteria in Table 3, as mentioned above. The average scores of the five components compared between the pre- and posttests are shown in Figure 3.

All students could express a claim. Moreover, $93 \%$ of students could give at least one justificatory reason as a warrant

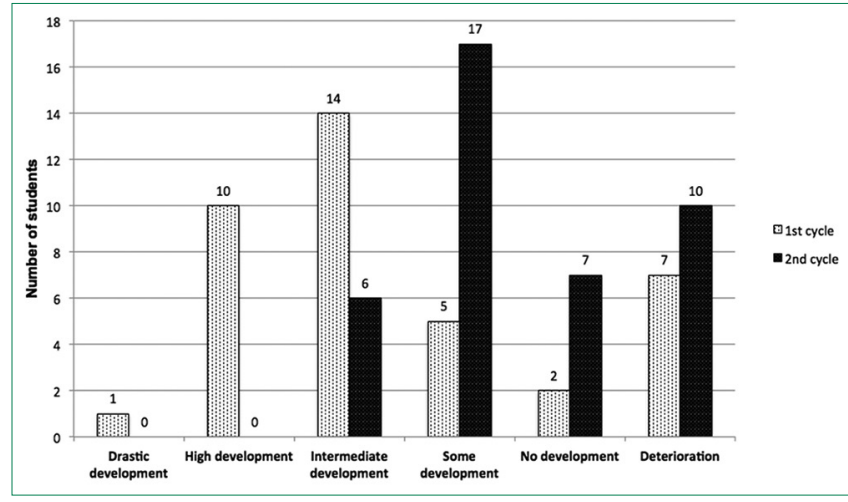

Figure 2: Students at each level of argument skills development in both the cycles

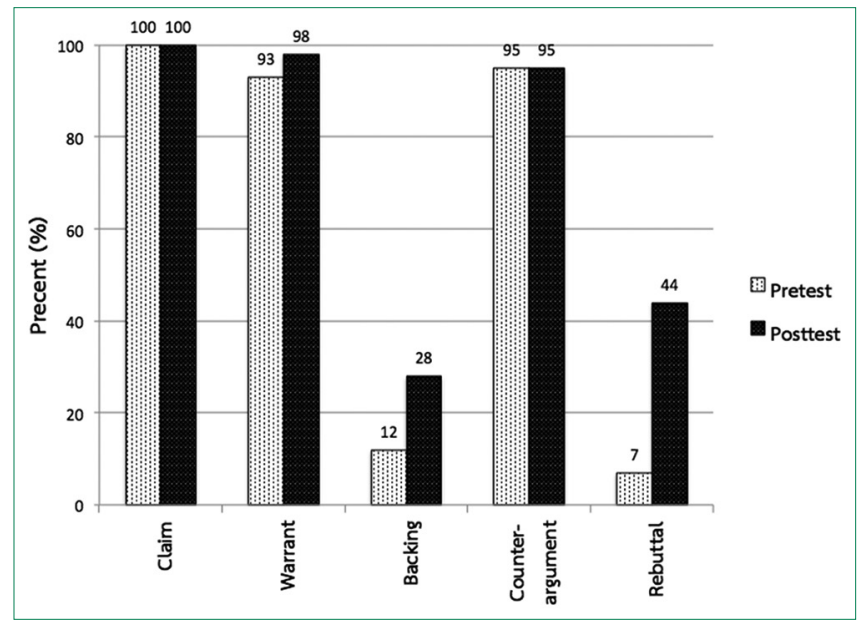

Figure 3: Percentages of students at level $A$ and above for the components in the pre- and posttests for the first cycle 
supporting their claim in the pretest and $98 \%$ in the posttest, as shown in Figure 3. In addition, 5\% gave non-justificatory reasons in the pretest, while there were none in the posttest, as shown in Figure 4. Moreover, the number of students providing only one justificatory reason decreased, while there was an increase in students offering more than one justificatory reason in the posttest.

The students' justificatory reasons had various aspects, such as economic, environmental, living, rules and laws, and moral aspects (Table 4).

Most justificatory reasons in the pre- and posttests were related to economics. For example, the reason supporting the Thai oil fund's abolishment was that the country would have less debt. The second most common justificatory reason concerned the environment. An example reason for supporting the Thai oil fund's abolishment was that the oil fund helped persuade people to use alternative energies, such as gasoline E20 and E85.

The difference between the pre- and posttests was that nobody gave a moral warrant in the former, while $4 \%$ of students gave moral warrants in the latter.

Backings moderately developed in the first cycle (Figure 5), because students changed the answer from "Nothing" to something that was not a backing (Group B), as shown in Figure 5.

In the pretest, most students fell into Group C, answering "nothing" or not answering at all. In the posttest, most students moved to Group B, answering something besides a backing, such as (1) source of information for warrants (TV, internet, and newspaper) or (2) elaboration of warrant or no additional data to make it more reliable. An example is as follows:

- Claim: Disagree with the Thai oil fund's abolishment.

- Warrant: The Thai oil fund helped persuade people to use alternative energy.

- Backing: Using gasoline E20 and E85 can reduce fossil fuel consumption (elaboration of how good the warrant was).

\section{Table 4: Percentages of each aspect of justificatory} reasons

\begin{tabular}{lcc}
\hline Aspects & Pretest (\%) & Posttest (\%) \\
\hline Economic & 57 & 53 \\
Environmental & 28 & 24 \\
Living & 13 & 2 \\
Rules and laws & 2 & 14 \\
Moral & 0 & 7 \\
\hline
\end{tabular}

Table 5: The percentages of all subgroups for backings

\begin{tabular}{lcc}
\hline Subgroup & Pretest (\%) & Posttest (\%) \\
\hline Occurrences & 74 & 38 \\
Economic & 0 & 38 \\
Laws & 0 & 24 \\
One's experiences & 26 & 0 \\
\hline
\end{tabular}

In the posttest, $5 \%$ of students could give two backings for their warrants. These students were the representatives in the debate and might have had a lot of useful information. The increase of students in Group A for backings from 12\% to $28 \%$ might have been due to step 4 of the first cycle (debate). The opinions in students' reflective journals about how their argument skills had improved showed that they had learned backing from this step of the first cycle, as shown below:

- I learned that I should have more reasons to argue and find more backings to make the reasons more reliable.

- I learned that an argument must be composed of a warrant and backing so that the argument is strong.

The characteristics of backings in Group A were divided into various subgroups, such as occurrences, economic, laws, and one's experiences. The percentage of each subgroup is shown in Table 5.

In both the pre- and posttests, students tended to use occurrences they had heard before to back up their warrant. For example, a student wanted to back up the warrant that "the oil fund is illegal;" therefore, she applied the occurrence that the ombudsman sued the Thai oil fund for misappropriate administration.

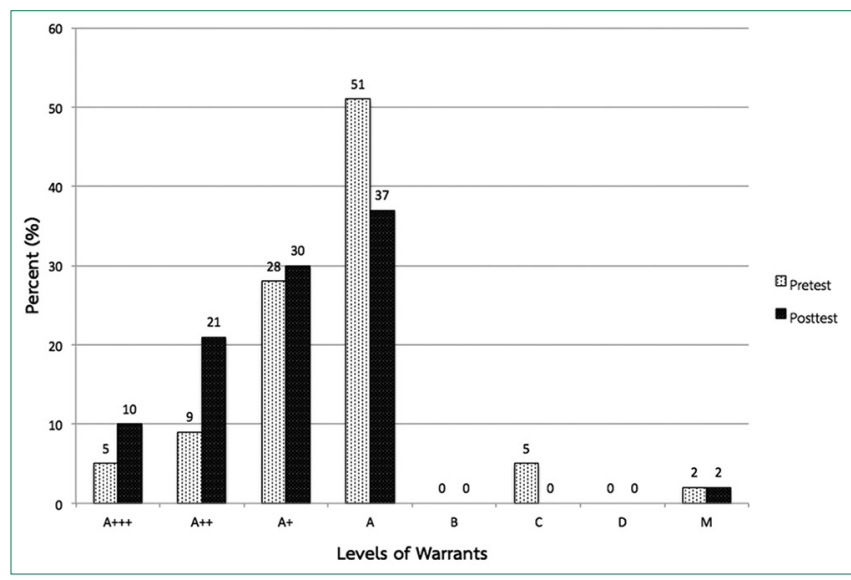

Figure 4: Pre- and posttest results of percentages of students at each level of warrants, from $\mathrm{A}+++$ to $\mathrm{M}$

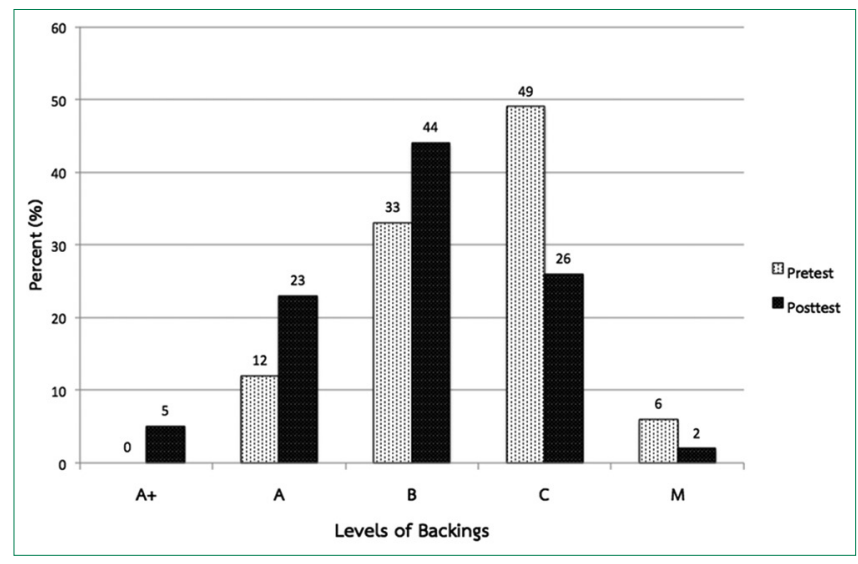

Figure 5: Percentages of students at each level of backings, from $A+$ to $\mathrm{M}$, in the pre- and posttests 
In the pretest, nobody used laws to back up warrants; however, in the posttest, up to $24 \%$ of students applied legal matters as backings.

Furthermore, the counterarguments showed a significant improvement in the posttest, as shown in Figure 6.

As Figure 6 shows, the percentage of students that could provide two counterarguments $(\mathrm{A}+)$ increased from $14 \%$ in the pretest to $53 \%$ in the posttest. The students at level $\mathrm{A}++$, who could provide three counterarguments, showed an increase from $2 \%$ in the pretest to $12 \%$ in the posttest. The results suggest that the students learned a lot about what others thought in the first cycle. Figure 6 also shows that the students' rebuttals improved, with more students making relevant and clear rebuttals (level A).

The percentage of students at level A for rebuttals increased from $7 \%$ to $44 \%$, respectively, in the pre- and posttests (Figure 7).

In the pretest, most students rebutted with irrelevant but clear rebuttals $(53 \%)$ and then rebutted with relevant and clear rebuttals in the posttest (42\%). In particular, the posttest results show that $2 \%$ of students were at $\mathrm{A}+$ level, using two relevant and clear rebuttals. For example, one student provided the following counterargument:

\section{Counterargument}

If the Thai oil fund was abolished, there could be no corruption in the Thai oil fund.

\section{Rebuttals}

If petroleum prices were cheaper, people would carelessly use petroleum-based fuel. Then, we would run out of oil. Finally, the price of oil would dramatically increase, and we could not afford it (Rebuttal 1). In the case of corruption, it would be better to improve the administration than abolish it (Rebuttal 2).

In the pretest, students' rebuttals conveyed some misconceptions, but this did not occur in the posttest. An example of such a misconception in a rebuttal in the pretest is as follows:

If we had no oil fund when the world prices of petroleum increase, we would have to spend more money on fuels while having the same cost of living.

The rebuttal was classified as a misconception because the cost of living would increase if the oil price increased.

\begin{tabular}{|c|c|c|}
\hline Patterns & Pretest (\%) & Posttest (\%) \\
\hline $\begin{array}{l}\text { Rebut using a weak } \\
\text { counterargument }\end{array}$ & 100 & 50 \\
\hline $\begin{array}{l}\text { Rebut by disproving the } \\
\text { counterargument }\end{array}$ & 0 & 30 \\
\hline $\begin{array}{l}\text { Rebut with a better solution than } \\
\text { that in the counterargument }\end{array}$ & 0 & 20 \\
\hline
\end{tabular}

The characteristics of relevant and clear rebuttals could be classified into three patterns. The percentages of each pattern are shown in Table 6.

In the posttest, students rebutted in various patterns, in contrast to the pretest, in which they only rebutted using weak counterarguments. After the first cycle, students learned how to refute others by finding solutions that were better than the counterargument. Moreover, some students could rebut by reconsidering the strong point of the counterargument and reflect by showing that the strong point actually was the drawback. That is, they could disprove the counterargument from the other. This could indicate that the students' thinking became deeper and broader.

\section{Argument Skills in the Second Cycle}

This cycle assessed students' argument skills through ASQ on the topic of whether a coal-fired power plant should be constructed in Krabi Province. The students had less development in the components of an argument as compared to the first cycle, as shown in Figure 8.

Figure 8 indicates that all students could make a claim. In the pretest, $90 \%$ of students expressed at least one justificatory

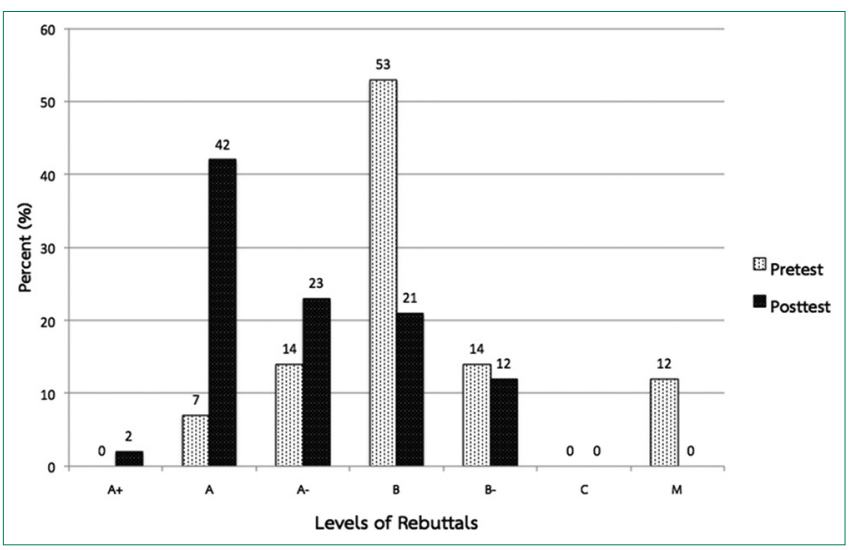

Figure 6: Pre- and posttest results for percentages of students at each level of counterargument, from $\mathrm{A}+++$ to $\mathrm{M}$

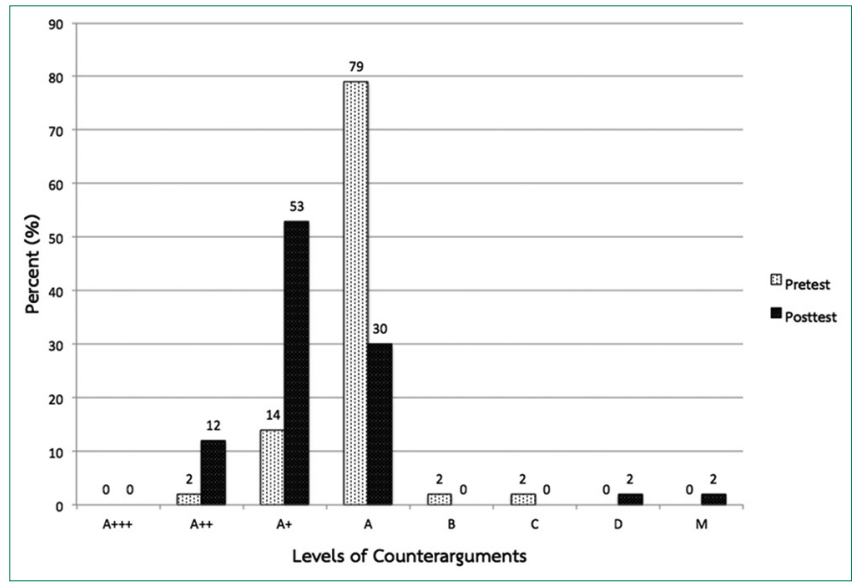

Figure 7: Comparison of percentages of students' rebuttals in the pre- and posttests 
reason (Groups $\mathrm{A}+++, \mathrm{A}++, \mathrm{A}+$, or $\mathrm{A}$ ), and this grew to $98 \%$ in the posttest.

Only 5\% showed a misconception in their reasons in the pretest, and none did this in the posttest, as shown in Figure 9.

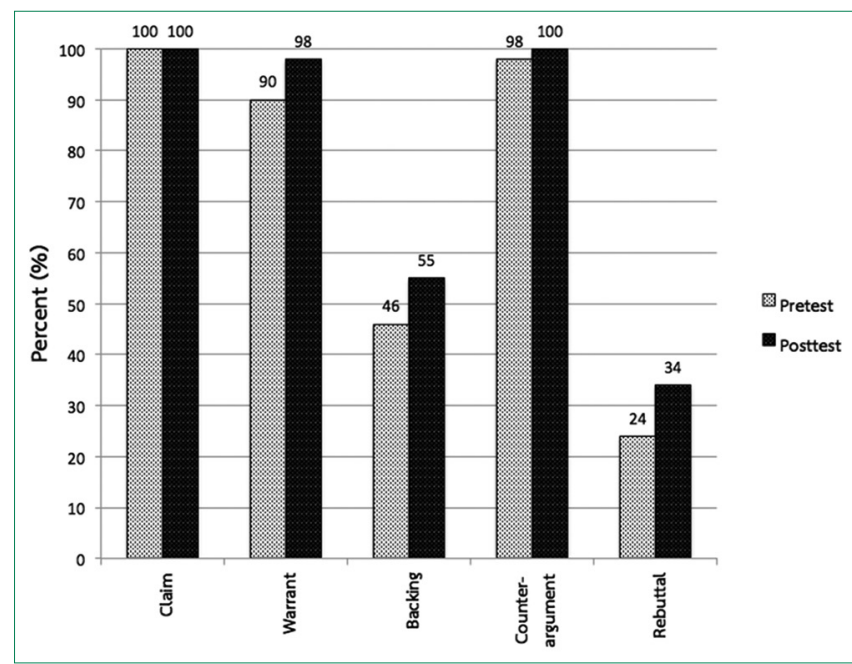

Figure 8: Percentages of students at level $A$ and above for the components in pre- and posttests in the second cycle

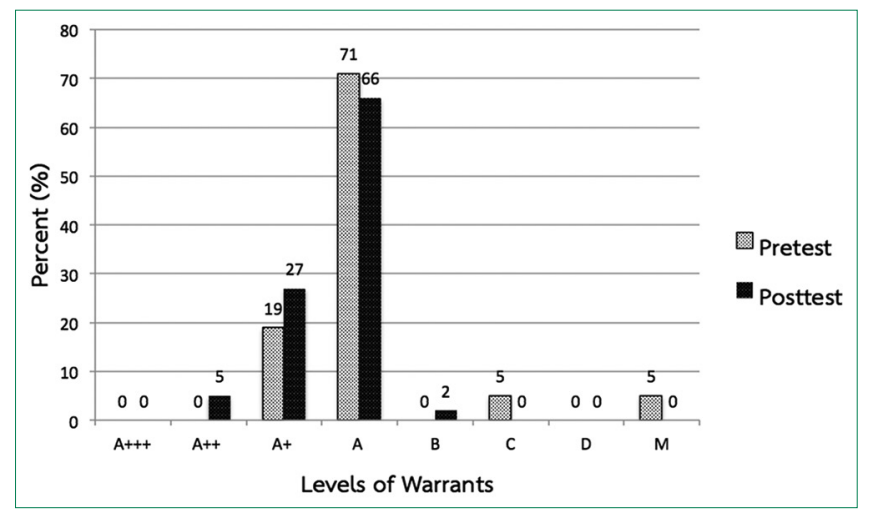

Figure 9: Percentages of students at each level of warrants, from $\mathrm{A}+++$ to $\mathrm{M}$, in the pre- and posttests

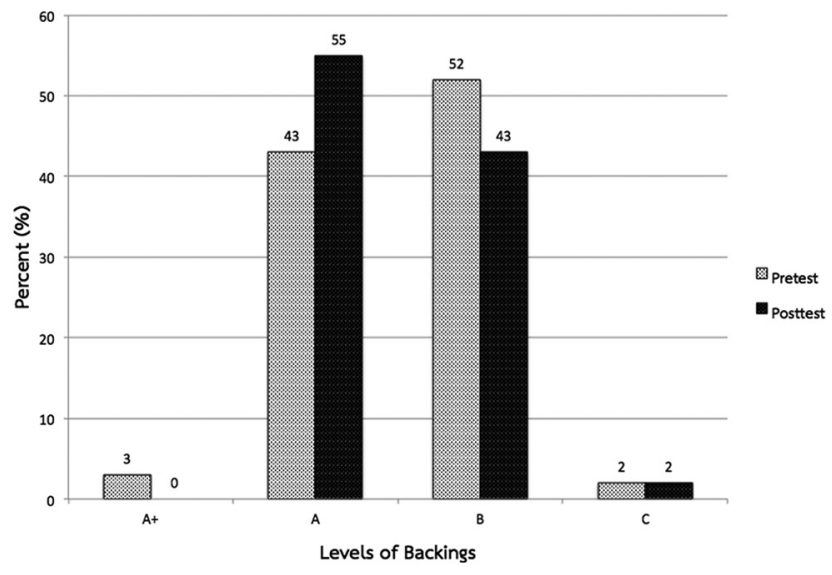

Figure 10: Percentages of students at each level for backings
Furthermore, $5 \%$ could support a claim with three warrants in the posttest.

The justificatory reasons could be classified into four aspects: Economic, living, environmental, and technological aspects. The percentages of each aspect are shown in Table 7.

Students expressed the greatest concern for the environment in both the pre- and posttests, followed by economic and living aspects.

Students gave more backings in the posttest, while in the pretest, they had tended to answer with something else, like the source of the information and elaboration, as shown in Figure 10.

Backings were classified into many categories. The most popular category in both the pre- and posttests was the problems of an existing coal-fired power plant in Thailand's Lampang Province, as shown in Table 8. Students tended to refer to illness caused by pollution from the power plant.

In the pretest, $20 \%$ of students backed up warrants with economic data and $16 \%$ used scientific data. The results show an increase in the number of students applying scientific data as backings in the posttest.

Moreover, $98 \%$ and $100 \%$ of students could deploy counterarguments in the pre- and posttests, respectively (Figure 11).

Compared to the posttest of the first cycle, $53 \%$ of students could use two counterarguments (Group A+), while this figure was only $7 \%$ in the second cycle. A possible explanation is that the students did not practice using a two-side supportive worksheet. This will be discussed in section 3.3.

For rebuttals, a slight increase in students $(8 \%)$ which could employ relevant and clear rebuttals was observed in the posttest, as shown in Figure 12.

Table 7: Percentages of all aspects of the justificatory reasons

\begin{tabular}{lcc}
\hline Aspects & Pretest (\%) & Posttest (\%) \\
\hline Economic & 56 & 39 \\
Environmental & 21 & 31 \\
Living & 21 & 28 \\
Technological & 2 & 2 \\
\hline
\end{tabular}

Table 8: Percentages of the categories of backings

\begin{tabular}{lcc}
\hline Categories & Pretest (\%) & Posttest (\%) \\
\hline $\begin{array}{l}\text { The problems of an existing } \\
\text { coal-fired power plant in Thailand }\end{array}$ & 46 & 56 \\
$\begin{array}{l}\text { Economic data } \\
\text { Scientific data }\end{array}$ & 20 & 0 \\
$\begin{array}{l}\text { Others (geographic data, other } \\
\text { country with a coal-fired power } \\
\text { plant, rate of power usage, and } \\
\text { personal experiences) }\end{array}$ & 16 & 29 \\
\hline
\end{tabular}




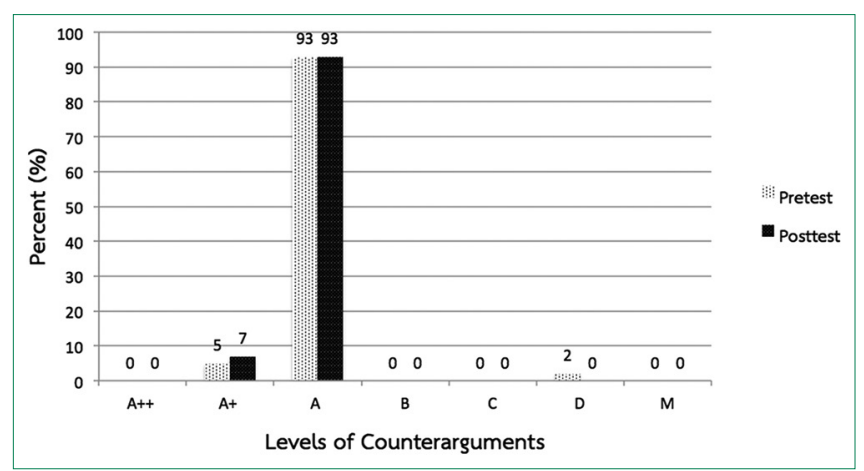

Figure 11: Percentages of students at each level of counterarguments in the pre-and posttests

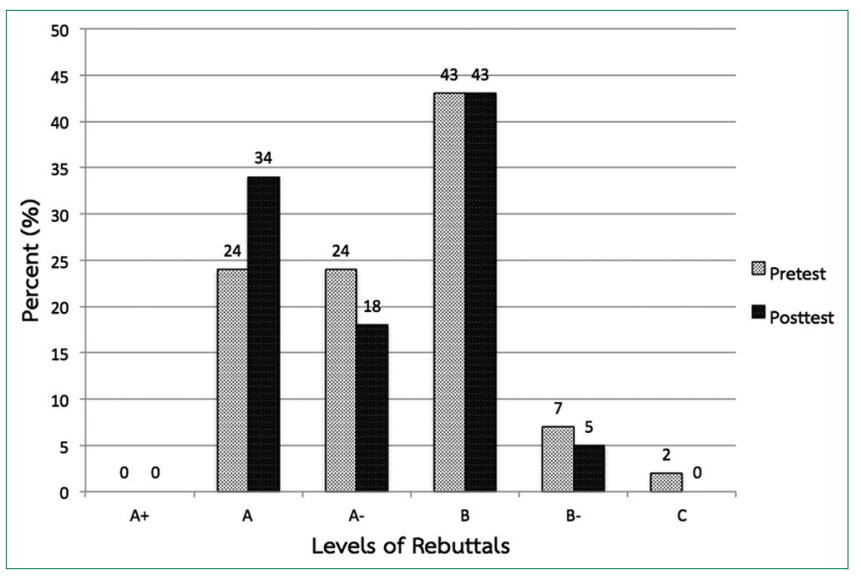

Figure 12: Percentages of each level of rebuttal

The patterns of relevant and clear rebuttals were classified into three patterns for the first cycle: (1) Rebut by showing the weak point of the counterargument, (2) rebut by disproving the counterargument, and (3) rebut by offering a better solution than that in the counterargument. The percentages of each pattern of relevant and clear rebuttals are shown in Table 9.

After the second cycle, students had learned some information that helped them rebut a counterargument by disproving it. The improvement of the rebuttals in the second cycle ( $8 \%$ increase) was less than in the first cycle ( $35 \%$ increase). This issue will be discussed in section 3.3.

Regarding the five components of argument skills, students had improved some characteristics that enhanced their argument skills. The data from students' reflective journals reveal that they improved in self-confidence, assertiveness, manner of speaking and listening, and class participation.

- I have developed my self-confidence and have participated more in class.

- We should not make ourselves the center of the universe. We should listen to other options.

- I have learned the manner of speaking and listening.

- I am a reserved person, so I do not talk much. However, when the teacher assigns public speaking, I have more confidence to speak in class.
Table 9: Percentages of patterns of relevant and clear rebuttals

\begin{tabular}{lcc}
\hline Patterns & Pretest (\%) & Posttest (\%) \\
\hline $\begin{array}{l}\text { Rebut by showing the weak point of } \\
\text { the counterargument }\end{array}$ & 40 & 40 \\
$\begin{array}{l}\text { Rebut by disproving the } \\
\text { counterargument }\end{array}$ & 10 & 40 \\
$\begin{array}{l}\text { Rebut by offering a better solution } \\
\text { than that in the counterargument }\end{array}$ & 50 & 20 \\
\hline
\end{tabular}

Best Practices for Improving Students' Argument Skills I sought the best practices for improving Grade 12 students' argument skills and teaching the learning unit on fossil fuels and their products. The teaching results were collected from my reflective journals and those written by the students after every step of each cycle. Inductive analysis was carried out on the data to elicit the pros and cons of each step. The best practices comprised four steps of teaching: (1) Use good SSI, (2) inform students' knowledge of SSI, (3) scaffold knowledge, and (4) construct an argument.

\section{Use Good SSI}

SSI was applied as the context of learning science and argument skills for a whole cycle; thus, it needed to be attractive to the students. I identified some characteristics that made SSI attractive. For example, it was directly involved in students' lives and evoked their feelings. Moreover, SSI needed to be connected to the class objective(s) to allow students to learn the science content.

\section{Direct Involvement in Students' Lives}

The direct involvement of SSI in the students' lives meant the potential to change their way of living. In the first cycle, SSI was about the problem of the Thai oil fund possibly affecting the price of petroleum. Then, the prices of goods and services would be affected, and finally, this would affect the students' living expenses.

As shown in my reflective journal for step 1 of the first cycle, half of the class had never heard of the Thai oil fund and the other half had heard of it but did not know what it was. Part of the reflective journal was translated and is shown below:

This made me quite surprised when I had been teaching that class. Hence, I asked them what they would do if they were watching TV and the economic news came on. The students answered all together, "Change the channel." That meant that the issue I was using was not interesting to them.

\section{Evoke Students' Feelings}

The SSI might not have directly affected the students' lives, but if it evoked feelings in them, it would be attractive to them. The SSI could be related to humanity and environment. In the second cycle, I applied the SSI concerning a coal-fired power plant in Krabi Province to teach about coal and the pollution from producing and using petroleum products. I asked if any of my students had heard about petroleum related to coal-fired power 
plants. Many students said "yes" and some named Mae Moh Power Plant in Lampang Province. This was despite the fact that the incident at this coal-fired power plant had occurred in 1995, before they were born. The situation in Mae Moh district was severe; some local people died and many people had chronic respiratory disease. This influenced the students' feelings.

\section{Connect to Class Objectives}

The learning indicator of the Thai science curriculum in Grades 10-12 related to my lesson. The class objectives were (1) to search and explain the origin of petroleum, natural gas separation, and fractional distillation of crude oil and (2) to search and discuss applications of products from natural gas and fractional distillation of crude oil. The issue raised in the class, which was related only to some of the class objectives, was whether LPG or CNG is suitable for vehicles. With the numerous objectives that I had to cover within a limited time $(9 \mathrm{~h})$, the students had to study more science content than needed for SSI.

This made the SSI classroom feel like it was not real because the students did not quite learn through SSI; rather, they got the topics from me. Finding SSI that relates to many objectives is difficult, as one SSI tends to relate to one objective. Therefore, to cover all aspects of SSI, we need many issues, which consume a lot of class time. Therefore, I was confronted with how to reduce the time consumed in the SSI classroom and whether the SSI technique is suitable for Thai science classrooms.

\section{Inform Students' Knowledge of SSI}

If students do not have background knowledge relating to an issue, they cannot make an argument (Osborne et al., 2004). Common presentation is not enough to help students learn because only a few of them will take responsibility for the presentation, while the rest will not do anything to learn. Therefore, effective rules and journals are important to help every student in the group work and learn the necessary background knowledge. The rules applied in step 2 of the first cycle were (1) everyone in the group needed to take part in the presentation, (2) every group needed to ask at least one question to the presenting group, and (3) students needed to note what they had learnt from the presentation in a journal and hand it in right after class.

In class, I noticed that, while some students were presenting, others could not keep up, and they asked the presenter to repeat the information. Then, when they understood, they could write the journal entry. Thai students are always shy to ask questions or give their own opinions; therefore, if they had no task on which to do the journal entries, they would have just kept quiet.

In the second cycle, I improved the journal entries from the first cycle by adding subtopics to guide the students on what they needed to learn. This helped students learn the matter related to specific scientific content. As in the first cycle, there were no subtopics to guide the student in what they should focus on, resulting in very short and rough journal entries.
In class, I noticed some students asking their friends about the given subtopics that had not been mentioned. This meant that they could learn focused content.

The rule used in step 2 of the first cycle was that every question to the presenters earned bonus points for the whole group that asked. The students' reflective journals showed that the rules encouraged them to learn from the presenter are as follows:

This class encouraged me to question.

I was impressed that every group asked the presenters questions. This made the class lively and made me understand the lesson clearly.

Furthermore, rules were used in step 3 of the first cycle. The students shared the pros and cons for both sides. The rule was that every supporting statement that the students shared with the class earned their group points. This encouraged competition in the classroom, which made the students energetic about sharing information. Caution was taken in applying this rule, as not all 46 students could speak at the same time; therefore, the criteria for granting permission had to be impartial.

A problem that I faced with sharing information was that, sometimes, students shared incredible information just to get the points. For example, starvation was put forward as a drawback of the Thai oil fund. Astonished by this statement, I asked for clarification on how this could happen. The student tried to explain that the oil fund made diesel and gasoline more expensive; consequently, people had to pay a lot of money for fuel, leaving them with no money for food, and hence they would starve to death. To make the sharing activity more efficient, teachers should prepare strategies beforehand for dealing with this kind of problem.

\section{Scaffold Knowledge}

SSI involves a broad, complex, and controversial issue. Therefore, to learn through SSI, students need to collect and study a lot of information. This can confuse them. In the first cycle, a two-side supportive worksheet could help them scaffold the considerable information by writing down the pros and cons of both sides, as shown in Table 10 .

\begin{tabular}{lll}
\hline Table 10: & Example of the two-side supportive worksheet \\
\hline Options & Thai oil fund abolishment & \\
\cline { 2 - 3 } & Agree & Disagree \\
\hline Pros & $\begin{array}{l}\text { The price of petroleum } \\
\text { will decrease }\end{array}$ & $\begin{array}{l}\text { People continue using } \\
\text { alternative energies }\end{array}$ \\
& $\begin{array}{l}\text { The debt of the country } \\
\text { will lessen }\end{array}$ & $\begin{array}{l}\text { Farmers who grow cassava } \\
\text { and oil palm have high }\end{array}$ \\
& $\begin{array}{l}\text { income } \\
\text { Ceople will not use } \\
\text { alternative energies }\end{array}$ & $\begin{array}{l}\text { The country's debt will } \\
\text { increase every year }\end{array}$ \\
& $\begin{array}{l}\text { If the world price } \\
\text { fluctuates, there will be } \\
\text { no oil fund to control the } \\
\text { oil price in the country }\end{array}$ & $\begin{array}{l}\text { Unfair to the people who pay } \\
\text { the extra money to subsidize } \\
\text { the costs of alternative } \\
\text { energies }\end{array}$ \\
\hline
\end{tabular}


In the second cycle, the students did not use the twoside supportive worksheet because they only studied the information related to their public speaking role. Thus, they did not acquire information to support the claim (warrant). This might explain why the average score for warrants in the second cycle was lower than that in the first cycle (Figures 4 and 8).

Not only should students scaffold information as warrants but they should also use backings to support each warrant. This can help them revise their warrants and determine how many backings they must use to make their argument.

\section{Construct an Argument}

Students should have a chance to practice arguments by sharing the pros and cons for both sides. Sharing this information helped my students conceive broader information by interacting with their friends in the form of social constructivism. Further, they developed confidence from activities that encouraged everyone to express their opinions. Finally, practicing supporting and refuting both sides let them consider and value their own and friends' information. Evidence supporting the advantages of sharing information was raised in students' reflective journals as follows:

This class helps me be more confident about expressing my opinions among friends.

- I can give opinions that are different from other people's opinions.

- I got new information from friends in class.

- The teacher asking me to elaborate on my opinion made me consider it in more detail.

In the study, I had the students argue effectively by arranging the debate that it was natural and free. The arrangement of the debate was that there were three representatives from both sides. They took turns arguing, where the leader had $5 \mathrm{~min}$, and each other group member had $3 \mathrm{~min}$. After they went through the first part of the debate, they had a chance to debate more freely. The students argued, but the time was not counted. The debate ended when there was no new issue to debate. This section of the debate showed that the students practiced many rebuttals, whereas there had been few rebuttals in the first part of the debate. An example of a student's rebuttal was transcribed and translated as follows:

- The side that disagreed with the Thai oil fund's abolishment:

- If you want to abolish the Thai oil fund because of the corruption in the organization, why not consider setting up a committee to investigate it? Then you will know whether there is corruption in the Thai oil fund.

The side that agreed with the Thai oil fund's abolishment:

When Thaksin Shinawatra was Prime Minister of Thailand, juridical councils were set up to inspect the Thai oil fund. They found that there was corruption in the organization. Did you know this?

This debate helped the students develop their argument skills.
Teaching observation and the students' reflective journals revealed the following benefits of the debate class.

1. Help the students know more backings

The results from ASQ in the first cycle showed that the students considerably developed in the backing component. Their reflective journals revealed that debate helped them learn backings as follows. For example, a student wrote, "I learned backings in the debate from the side that agreed with the Thai oil fund's abolishment."

2. Help the students be aware of controlling their temper

In their reflective journals, some students mentioned that they were sentimental and should control their temper better than they did during the debate. This reflects the development of an important characteristic for supporting argument skills.

3. Help the students be aware of the importance of backings

The students' reflective journals revealed that they realized that backings are important for constructing credible arguments, as shown below. For example, a student wrote, "The debate helped me know that I should have warrants and backings to make my argument credible."

4. Help the students be aware of the importance of rebuttals

The students' reflective journals evinced learning about the importance of rebuttals. For example, a student wrote, "I learned that I should study more information in order to rebut others."

5. Help the students learn rebuttals

Many rebuttals that the students gave in ASQ came from the dialogue that occurred in the debate. The video recorded during the debate showed the rebuttal between the sides that agreed and disagreed with the Thai oil fund's abolishment as follows:

- The side that agreeds with the Thai oil fund's abolishment:

The Thai oil fund is useless. It only causes an increase in petroleum prices. Moreover, the political party seeks to benefit by misusing through populist policies.

- The side that disagreed with the Thai oil fund's abolishment:

Even if the Thai oil fund was abolished, the politicians would still find benefits from some other organizations.

The debate helped students in many aspects because they applied the information they had obtained to formulate arguments. However, the public speaking aspect did not really help the students in creating their arguments since they were just reciting information they had prepared to share publically. They did not recognize either warrants or counterarguments because the audience felt bored with the speakers and did not listen. Consequently, most students did not improve their argument skills as anticipated. The students' reflective journals also mentioned public speaking as follows:

- I would like my friends to speak with their understanding, 
not just read through a script.

- $\quad$ The argument was incoherent, and I could not understand what they were saying.

\section{CONCLUSIONS, DISCUSSIONS, AND RECOMMENDATIONS}

Science is a social activity that advances through discussion among people (Kuhn, 1991). Educational studies have shown that constructing arguments enhances the conceptual understanding of subject matter in school-age children and college students (Zohar and Nemet, 2002).

In this study, students' argument skills were developed by learning about fossil fuels and their products through SSI. In the first and second cycles, the majority had intermediate and some development, respectively. Considering the argument components, students did well in constructing claims, warrants, and counterarguments (more than 95\%), while not more than $60 \%$ could provide backings and rebuttals after each cycle.

The present work supports earlier findings that we need to use techniques, such as student presentations, group discussions accompanied by guidelines, and support for the appropriate argument skills (Osborne et al., 2004). Furthermore, teachers could support students by giving them feedback on their argument skills through ASQ. This would help students understand, for example, if they are good at constructing warrants or poor at making rebuttals. Thereby, they could further improve the poor component(s). Given the problem of distinguishing between data and warrants (Zeidler, 2003), the study excluded data. The argument components in the present study were claim, warrant, backing, counterargument, and rebuttal. I found that data and warrant can be distinguished and should be separate. For instance, a student disagreed with constructing a coal-fired power plant (claim) because of global warming (data). He used data (global warming) as a warrant, but he did not explain how global warming supported the utterance. Indeed, he did not answer the warrant but the data.

Voss and Means (1991) found that adolescents and young adults were unlikely to construct two-sided arguments. The present work successfully promoted two-side arguments through a two-side supportive worksheet, and the students provided reasons to support each side as warrants on this worksheet. Bell and Lin (2000) found that the process of building an argument might promote knowledge integration. They utilized a computer program to scaffold argument construction to make the thinking visible.

Not only should students scaffold warrants through a two-side supportive worksheet but also scaffold backings that support each warrant. Students can discuss several newspapers or some statistics to support their warrants in pairs or triads. This can help them revise what they have written down and how many backings they have used to make their argument. Moreover, students should evaluate and divide their warrants and backings as best, good, or okay (Kuhn and Udell, 2003;
Yilmaz et al., 2017).

In the step of constructing the argument, ground rules for evaluating an acceptable reason were ill-prepared. Some students felt that I was not being fair to them because some reasons were acceptable while some were not. In such a case, Mercer et al. (2004) suggested establishing an equitable intellectual environment with well-established ground rules.

When teaching argument skills, teachers should explicitly teach the components of an argument and make sure that the students understand their meanings and the relationships between them. Subsequently, the students can construct their own diagrams including all argument components. For example, students can show their data and link it to their utterance (claim). In between the data and claim, they can include warrants supported with backings. Then, they can add warrants for counterarguments to show that they know what reasons support other utterances. Finally, rebuttals can be added regarding the counterarguments to disprove them. This can advance their claims and undermine counterclaims. This is the way to practice a good quality argument.

After the first and second cycles, I found that up to $44 \%$ and $34 \%$ of students, respectively, could make rebuttals, while Kuhn and Udell (2003) found that, in argument discourse, the rebuttal sequence remained at a relatively low usage level (no greater than $5 \%$ ). The difference in percentages between the present study and Kuhn and Udell (2003) study is quite large because the data collection methods differed. Kuhn studied argument discourse. She collected data by audio taping the discourse of pairs of students, who could argue in many ways and might not have chosen to apply rebuttals to their arguments.

In real life, people argue through social interaction rather than through writing. To accurately assess argument skills, an assessment through dialogue is proposed. Moreover, argument skills are not absolute skills but a kind of performance that depends on cognitive construction or background knowledge (Kuhn and Udell, 2003). Yet argumentation is not limited to increasing cognitive skills; it becomes a more comprehensive interaction in which its validity depends on the acceptance of the audience (argumentation and education). Much less research has been devoted to argumentative discourse (argumentation) than to arguments that are cognitive constructions of individuals (Kuhn and Udell, 2003; Osborne et al., 2004).

\section{ACKNOWLEDGMENTS}

This research was supported by the Institute for the Promotion of Teaching Science and Technology as part of the scholarship project for the Promotion of Science and Mathematics Talented Teachers.

\section{REFERENCES}

Bell, P., \& Linn, M. (2000). Scientific arguments as learning artifacts: Designing for learning from the web with KIE. International Journal of Science Education, 22(8), 797-817.

Berk, L., \& Winsler, A. (1995). Scaffolding Children's Learning: Vygotsky 
and Early Childhood Education. Washington, DC: National Association for the Education of Young Children.

Berland, L.K., \& McNeill, K.L. (2010). A learning progression for scientific argumentation: Understanding student work and designing supportive instructional contexts. Science Education, 94, 765-793.

Brem, S.K., \& Rips, L.J. (2000). Explanation and evidence in informal argument. Cognitive Science, 24, 573-604.

Driver, R., Asoko, H., Leach, J., Mortimer, E., \& Scott, P. (1994). Constructing scientific knowledge in the classroom. Educational Researcher, 23(7), 5-12.

Erduran, S., \& Jimenez-Aleixandre, M.P. (2012). Argumentation in science education research: Perspectives from Europe. In: Jorde, D., \& Dillon, J., (Eds.). Science Education Research and Practice in Europe: Retrospective and Prospective. Rotterdam: Sense Publisher. pp. 253289

Kuhn, D. (1991). The Skills of Argument. Cambridge, England: Cambridge University Press.

Kuhn, D., \& Udell, W. (2003). The development of argument skills. Child Development, 74, 1245-1260.

Lin, S.S., \& Mintzes, J.J. (2010). Learning argumentation skills through instruction in socioscientific issues: The effect of ability level. International Journal of Science and Mathematics Education, 8, 9931017.

Maloney, J., \& Simon, S. (2006). Mapping children's discussions of evidence in science to assess collaboration and argumentation. International Journal of Science Education, 28, 1817-1841.

McNiff, J., \& Whitehead, J. (2005). Action Research for Teachers. London: Fulton.

Mercer, N., Dawes, L., Wegerif, R., \& Sams, C. (2004). Reasoning as a scientist: Ways of helping children to use language to learn science.
British Educational Research Journal, 30(3), 359-377.

Osborne, J.F., Erduran, S., \& Simon, S. (2004). Enhancing the quality of argumentation in school science. Journal of Research in Science Teaching, 41, 994-1020.

Oulton, C., Dillon, F., \& Grace, M. (2004). Reconceptualizing the teaching of controversial issues. International Journal of Science and Education, $26,411-423$.

Sadler, T.D. (2011). Socio-scientific issues-based education: What we know about science education in the context of SSI. In: Sadler, T., (Ed.). SocioScientific Issues in the Classroom: Teaching, Learning and Research Dordrecht: Springer. pp. 355-370.

Toulmin, S.E. (2003). The Uses of Argument. London, England: Cambridge University Press.

Voss, J., \& Means, M. (1991). Learning to reason via instruction in argumentation. Learning and Instruction, 1, 337-350.

Yilmaz, Y.O., Cakiroglu, J., Ertepinar, H. \& Erduran, S. (2017). The pedagogy of argumentation in science education: Science teachers instructional practices. International Journal of Science Education, 39(11), 1443-1464.

Zeidler, D.L. \& Nichols, B.H. (2009). Socioscientific issues: Theory and practice. Journal of Elementary Science Education, 21(2), 49-58.

Zeidler, D.L. (2003). The Role of Moral Reasoning on Socioscientific Issues and Discourse in Science Education. The Netherlands: Kluwer Academic Press.

Zeidler, D.L., Sadler, T.D., Simons, M.L., \& Howes, E.V. (2005). Beyond STS: A research-based framework for socioscientific issues education. Science Education, 89, 357-377.

Zohar, A., \& Nemet, F. (2002). Fostering students' knowledge and argumentation skills through dilemmas in human genetics. Journal of Research in Science Teaching, 39, 35-62. 